\title{
Drug-Induced Hypothermia as Beneficial Treatment before and after Cerebral Ischemia
}

\author{
Flemming F. Johansen ${ }^{a}$ Henrik Hasseldam ${ }^{a}$ Rune S. Rasmussen ${ }^{a}$ \\ Anne Sofie Bisgaard ${ }^{\mathrm{a}}$ Peter K. Bonfils ${ }^{\mathrm{a}}$ Steen S. Poulsen ${ }^{\mathrm{a}}$ \\ Jacob Hansen-Schwartz ${ }^{b}$
}

${ }^{a}$ Molecular Pathology, Biotech Research and Innovation Centre, Department of Biomedical Sciences, Faculty of Health and Medical Sciences, University of Copenhagen, Copenhagen, and ${ }^{\mathrm{b}}$ Department of Emergency Medicine, Køge Hospital, Køge, Denmark

\section{Key Words}

Cell density - Endothelial cells . Growth factor .

Hypoxia-ischemia · Necrosis · Pathogenesis · Pathology

\begin{abstract}
Objectives: Hypothermia is still unproven as beneficial treatment in human stroke, although in animal models, conditioning the brain with hypothermia has induced tolerance to insults. Here, we delineate the feasibility of drug-induced mild hypothermia in reducing ischemic brain damage when conditioning before (preconditioning) and after (postconditioning) experimental stroke. Methods: Hypothermia was induced in rats with a bolus of $6 \mathrm{mg} / \mathrm{kg}$ talipexole followed by $20 \mathrm{~h}$ continuous talipexole infusion of $6 \mathrm{mg} / \mathrm{kg}$ in total. Controls received similar treatment with saline. The core body temperature was continuously monitored. In preconditioning, hypothermia was terminated before either reversible occlusion of the middle cerebral artery (MCAO) for $60 \mathrm{~min}$ or global ischemia for $10 \mathrm{~min}$ with 2-vessel occlusion and hypotension. In postconditioning, rats experienced $60 \mathrm{~min}$ of MCAO before hypothermia was induced either immediately or with $3 \mathrm{~h}$ delay. Rats survived ischemia for 2, 7 or 90 days.
\end{abstract}

Infarct volumes were quantified by stereology. Additional experiments of methodological relevance were included in the study. Results: Talipexole induced mild hypothermia $\left(35.1 \pm 1.1\right.$ to $36.0 \pm 0.5^{\circ} \mathrm{C}$ ) for $<20 \mathrm{~h}$. Hypothermic pre- and postconditioning reduced infarct sizes by more than $60 \%$ as monitored during the first 90 days after experimental stroke $(p<0.05)$. Conclusion: Talipexole is registered for use as a dopamine substitute in humans with Parkinson's disease. Although dosages cannot be directly translated to patients, our study exemplifies in an animal model that drug-induced hypothermia in a clinical setting might reduce cerebral ischemic damage before neuro- and cardiac surgical procedures and after stroke.

Copyright $\odot 2013$ S. Karger AG, Basel

\section{Introduction}

Only a small number of stroke patients benefit from thrombolysis due to a narrow therapeutic time window [1]. For the majority of patients, an alternative acute therapy is needed. Moreover, both neuro- and cardiac surgical procedures carry the risk of ischemic injury with sig-

\section{KARGER}

E-Mail karger@karger.com www.karger.com/pat (c) 2013 S. Karger AG, Basel

1015-2008/14/0811-0042\$39.50/0 
nificant implications for mortality and morbidity [2]. Also, $42 \%$ of coronary artery bypass patients suffered from neurocognitive deficits 5 years after surgery [2]. From a social and an economical point of view, it is important to develop new therapeutic strategies that can be applied before (preischemic) and after cerebral ischemia (postischemic) in order to attenuate brain damage.

Ischemic tolerance can be induced if the brain is subjected to a weak ischemic stimulus prior to (preconditioning) or after (postconditioning) the primary ischemic insult [3]. Due to cross-tolerance, hypothermia as conditioning stimulus can also elicit such a transient adaptive cellular response, promoting tolerance towards ischemia [4]. Hypothermia is one of the most promising neuroprotective therapies, as assessed by the Stroke Therapy Academic Industry Roundtable criteria [5], affects a wide range of cell death mechanisms and has a broad safety margin [6-11]. Altogether, data suggest that mild to moderate hypothermia is a promising and safe conditioning stimulus in patients with cerebral ischemia.

So far, in most clinical studies, the target temperatures have been moderate hypothermia. Cooling to $32-34^{\circ} \mathrm{C}$ is related to serious adverse events and requires admission to an intensive care unit [9-11]. Evaluating animal models of acute ischemic stroke, a meta-analysis of hypothermia effects concluded that cooling to $35^{\circ} \mathrm{C}$ consistently reduced the infarct volume [12]. Thus, use of mild prolonged druginduced hypothermia may help to overcome the abovementioned obstacles. We have previously shown that the dopamine $\mathrm{D}_{2}$ receptor agonist, talipexole, induced hypothermia and significantly reduced small infarcts in experimental stroke, as compared to controls [13]. Talipexole was chosen because it is registered for use as a dopamine substitute in humans with Parkinson's disease; therefore, results in our present study may more easily be extended to a clinical setting compared to using non-registered compounds.

This talipexole-induced hypothermic regime has been studied by us in moderately sized cortical infarcts in rats treated with hypothermia before and after cerebral ischemia.

In preconditioning experiments, we investigated the effects of drug-induced hypothermia given before cerebral ischemia in two well-known models of either 60-min middle cerebral artery occlusion (MCAO; infarct size $<45$ $\mathrm{mm}^{3}$ ) or 10 min of global cerebral ischemia (2-vessel occlusion model with hypotension; hippocampal CA1 infarction). This part of the study mirrors neuro- and cardiac surgical procedures in patients where drug-induced hypothermia as a preconditioning stimulus may be used prior to surgery to reduce cerebral ischemic damage.
In postconditioning experiments, we investigated if drug-induced hypothermia could also be used after MCAO and still permanently reduce brain damage, even if the infarct size was assessed as long as 90 days after the insult or if treatment was delayed for $3 \mathrm{~h}$ after the experimental stroke. This second part of the study exemplifies that drug-induced hypothermia as a postconditioning stimulus may be given to stroke patients immediately at pick-up for hospitalization and may thereby both shorten the time to treatment, and possibly, also expand the therapeutic window for other treatments at the hospital.

As proof of principle, and supplementary to methodological questions, we investigated if hypothermia could be considered the primary cause of infarct reduction when using talipexole. A group of rats were kept normothermic with a feedback heating lamp during drug treatment after $\mathrm{MCAO}$, and then the infarct size was measured 7 days later. Further examinations of typical hypothermic conditioning effects were determined by measuring the presence of vascular endothelial growth factor (VEGF) in brains using Western blotting after animals without ischemia were treated with talipexole and allowed to survive for a further $24 \mathrm{~h}$. Additional methodological studies encompassed investigations of the influence of talipexole on mean arterial blood pressure, as well as measurements of the influence of cranial window temperatures on brain infarct sizes.

\section{Materials and Methods}

This study was approved and conducted according to guidelines by the Animal Research Committee of Copenhagen University (No. 2006/561-1263). All procedures including steps to eliminate animal suffering were carried out in accordance with the guidelines of the Faculty of Health and Medical Sciences, University of Copenhagen, Copenhagen, Denmark.

\section{Animals and Experiments}

Male Wistar Hannover rats approximately 3 months old and weighing between 280 and $340 \mathrm{~g}$ were used in all experiments. Animals were housed 2 per cage under a 12-hour light/12-hour dark cycle with free access to water and food. Talipexole was kindly supplied by Boehringer Ingelheim (Ingelheim, Germany). A total of 119 out of 135 animals were included in the study (for those excluded, see Results). All animals were treated and handled by investigators blinded to treatments. The study contained groups for treatment with talipexole before cerebral ischemia (preconditioning) as illustrated in figure 1 and for treatment with talipexole after cerebral ischemia (postconditioning) as illustrated in figure 2.

Proof of Principle: Studies $A$ and $B$

In study $A$, two groups of rats were kept normothermic with a feedback heating lamp during either drug or saline treatment after MCAO. After $60 \mathrm{~min}$ of MCAO, the rats received $20 \mathrm{~h}$ of con- 


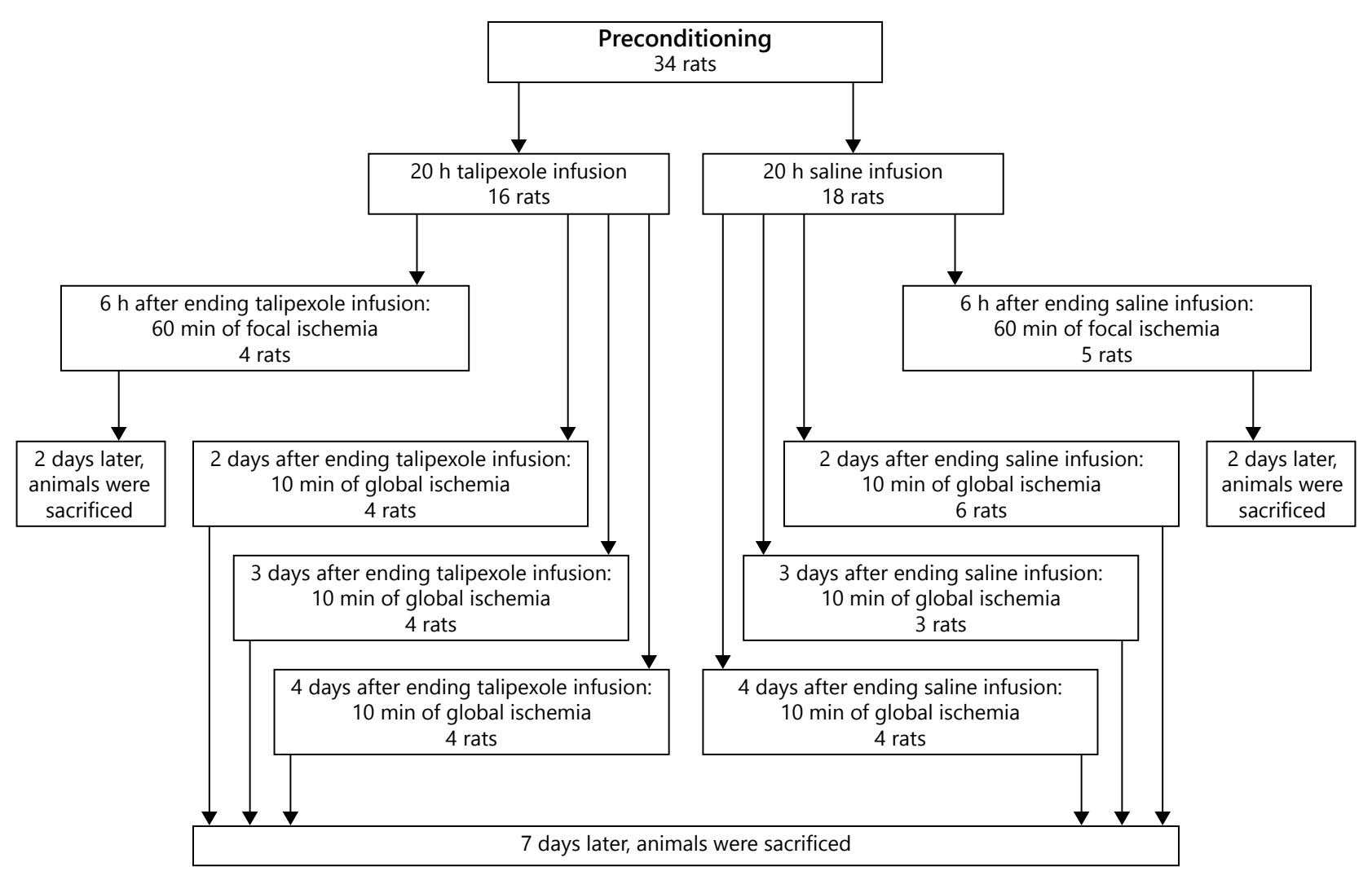

Fig. 1. An overview of the different groups included in the preconditioning study where talipexole was administered before cerebral ischemia.

tinuous infusion with talipexole $(n=7)$ or saline $(n=5)$ together with a temperature clamp (fan/heating lamp) between 36.5 and $37.5^{\circ} \mathrm{C}$ during the first $24 \mathrm{~h}$ after reflow, followed by 7 days survival.

In study $\mathrm{B}$, to investigate if talipexole induced hypothermia in itself without ischemia-promoted VEGF formation in the brain as indicator of conditioning, animals were solely treated with either talipexole $(\mathrm{n}=4)$ or saline $(\mathrm{n}=4)$, as described below, and allowed to survive for $24 \mathrm{~h}$ before the brains were taken out and prepared for Western blotting.

\section{Methodological Studies $C$ and D}

In study $\mathrm{C}$, the influence of talipexole infusion on blood pressure was tested. Rats were either subjected to $60 \mathrm{~min}$ MCAO ( $\mathrm{n}=$ $7)$ or sham operation $(n=3)$ followed by talipexole infusion for $20 \mathrm{~h}$ during which blood pressure was continuously measured in the first $24 \mathrm{~h}$. Animals were euthanized under deep anesthesia at the end of the experiment.

In study $\mathrm{D}$, the influence of the cranial window temperature on infarct size was also tested by subjecting rats $(\mathrm{n}=9)$ to $60 \mathrm{~min}$ MCAO and, at the same time, both the cranial window temperature and the rectal temperature were monitored. After 7 days survival, the infarct volumes were estimated in each animal.
Anesthesia, Physiological Variables and Temperature

Anesthesia was induced by brief exposure to $3 \%$ halothane in a $\mathrm{N}_{2} \mathrm{O} / \mathrm{O}_{2}(2: 1)$ mixture. The rats were intubated and further mechanically ventilated (New England Medical Instruments Inc., South Natick, Mass., USA) during surgery with $0.5-1 \%$ halothane in $\mathrm{N}_{2} \mathrm{O} / \mathrm{O}_{2}(2: 1)$.

The femoral vein was cannulized for continuous talipexole infusion (equal doses in all experiments as indicated below) initiated $30 \mathrm{~min}$ after MCAO or as indicated in figure 1 . The femoral artery was cannulized for monitoring of $\mathrm{pCO}_{2}, \mathrm{pO}_{2}$, blood gases, electrolytes and blood glucose (Radiometer ABL555; Radiometer Medical, Brønshøj, Denmark) before, during and immediately after surgery. The mean arterial blood pressure was measured during surgery in all rats and additionally during the first $24 \mathrm{~h}$ after reflow in experiment C. Long-term measurements of arterial blood pressure as well as intravenous drug infusion in freely moving rats were performed with catheters tunneled subcutaneously and exteriorized at the back of the neck in a lightweight tethering spring attached to a swivel device at the top of the cage (SAI Infusion Technologies, Libertyville, Ill., USA).

Rectal temperature was measured during surgery in all animals. A temperature sensor radio pill (TA-FA20; Data Sciences International, St. Paul, Minn., USA) was surgically placed in the 


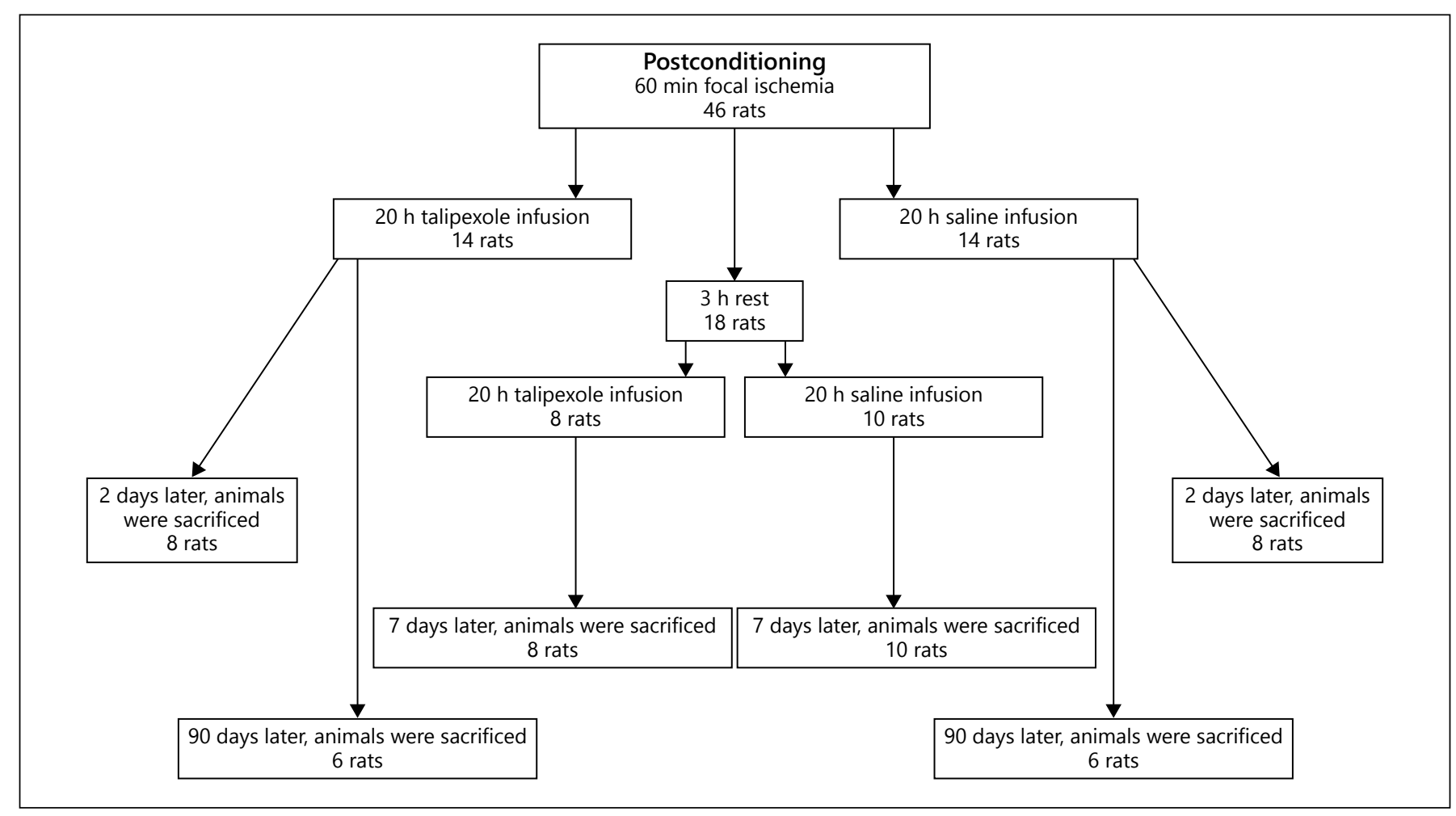

Fig. 2. An overview of the different groups included in the postconditioning study where talipexole was administered after cerebral ischemia.

peritoneal cavity of all rats for continuous recording of body temperature after surgery (Physio Tel Receiver RPC-1; Data Sciences International). In the additional $36.5-37.5^{\circ} \mathrm{C}$ temperature clamp in experimental group $\mathrm{A}$, the recording device further regulates (on/off) a fan and heating lamp placed above the animal, such that a temperature $<36.5^{\circ} \mathrm{C}$ turned on the heating lamp and a temperature $>37.5^{\circ} \mathrm{C}$ turned on the fan. In experimental group $\mathrm{D}$, an additional temperature probe was placed within the cranial window on the surface of the brain for simultaneous measurement of both the cranial window temperature and the rectal temperature.

\section{Surgical Procedures and Drug Administration}

For surgery, all rats subjected to MCAO were placed in a stereotaxic frame (David Kopf Instruments, Tujunga, Calif., USA) and then subtemporal craniotomy using sterile procedures for exposure of the left middle cerebral artery was performed $[13,14]$. The rectal temperature was monitored and kept within 36.5$37.5^{\circ} \mathrm{C}$ during the operation with a thermostatic feedback heating lamp. The arcus zygomaticus was trephined with an air-driven drill, and the main trunk of the middle cerebral artery was exposed and clamped distal to the striatal trunk for 60 min with a microsurgical hook guided by a micromanipulator (David Kopf Instruments). The cranial window was constantly covered with saline heated to $37.0^{\circ} \mathrm{C}$ throughout the operation. Reperfusion was established by removal of the hook around the middle cerebral artery, and halothane anesthesia was then turned off. Animals were removed from the stereotaxic frame after the end of MCAO and further ventilated with medical air until spontaneous respiration occurred within the first 10-15 min after disconnection of halothane. During this recovery period, incisions were quickly sutured after the skin was infiltrated with lidocaine $(20 \mathrm{mg} / \mathrm{ml})$.

Global ischemia was induced by 2 -vessel occlusion combined with systemic hypotension [14]. Both common carotid arteries were exposed and isolated using loose ligatures. Normal blood pressure was recorded and followed by exsanguinations from the arterial catheter to lower the blood pressure. The ischemic insult was initiated by tightening the carotid ligatures bilaterally for $10 \mathrm{~min}$. During the ischemic period, the blood pressure was maintained at $50 \mathrm{~mm} \mathrm{Hg}$ by withdrawal or infusion of blood. Ischemia was terminated by loosening the carotid ligatures and by slow reinfusion of exsanguinated blood, if necessary, supplied with slightly heparinized saline, to restore normotension. Anesthesia was promptly turned off and the animals were further ventilated with medical air until spontaneous respiration occurred within 10$15 \mathrm{~min}$. The skin was infiltrated with lidocaine $(20 \mathrm{mg} / \mathrm{ml})$ and the incisions were sutured.

Hypothermia was induced as previously described [13] in all experiments. According to body weight, talipexole rats received an intravenous bolus injection of $6 \mathrm{mg} / \mathrm{kg}$ talipexole [6-allyl-2-amino-5,6,7,8-tetrahydro-4H-thiazolo(4, 5-d)azepine dihydrochloride; Boehringer Ingelheim] dissolved in $0.5 \mathrm{ml}$ saline followed by continuous infusion for $20 \mathrm{~h}$ of a total of $6 \mathrm{mg} / \mathrm{kg}$ talipexole $\left(1 \mu \mathrm{h}^{-1} \mathrm{~g}^{-1}\right.$; concentration of $3 \mathrm{mg}$ talipexole dissolved in $10 \mathrm{ml}$ 
saline). Control rats received similar volumes of saline as a bolus and continuous infusion for $20 \mathrm{~h}$. In preconditioning experiments, talipexole or saline infusion was given after intravenous catheters were placed during anesthesia as described. In all other experiments, venous catheters were maintained for talipexole or saline infusion starting $30 \mathrm{~min}$ after reflow was established at the end of MCAO.

\section{Tissue Sampling and Estimation of Ischemic Damage}

All rats mentioned above were sacrificed under deep anesthesia (3\% halothane in 2:1 $\mathrm{N}_{2} \mathrm{O} / \mathrm{O}_{2}$ ) by transcardial perfusion with $4 \%$ phosphate-buffered formalin $(\mathrm{pH} \mathrm{7.2)}$. The brains were removed and further postfixed in formalin solution for $24 \mathrm{~h}$ at $4{ }^{\circ} \mathrm{C}$, then dehydrated and embedded in paraffin for coronal sectioning. At $100-\mu \mathrm{m}$ intervals, $10-\mu \mathrm{m}$-thick coronal sections were collected and stained with cresyl violet. Infarct size was quantified directly by computerized stereological examination (CAST-Grid; Olympus, Albertslund, Denmark) according to the principles of Bonaventura Francesco Cavalieri adjusted to the guidelines of Swanson et al. [15]. Briefly, the area of surviving tissue in the infarcted hemisphere is subtracted from the area of the contralateral noninfarcted hemisphere to get the infarct area used for volume calculation - hereby the influence of both edema and shrinkage becomes negligible. In global ischemia, $10-\mu \mathrm{m}$-thick coronal sections through the dorsal hippocampus were cut at $100-\mu \mathrm{m}$ intervals and stained with hematoxylin and eosin. CA1 pyramidal cells could be divided into neurons with unchanged morphology showing a distinct nucleus and nucleolus, and ischemic neurons with both shrunken cell body and fragmentized nucleus [14]. Based on the overall rostrocaudal extension of the ischemic CA1 pyramidal cell damage and number of cell loss, the degree of hippocampal CA 1 injury could be scored as $0=$ no ischemia, $1=$ mild ischemia, $2=$ moderate ischemia, and $3=$ severe ischemia. This scoring system has previously been evaluated in detail in our model [14]. Briefly, we compared whether counting surviving hippocampal CA1 neurons, or counting neurons with ischemia, or estimating the volume of ischemic CA1 damage, or scoring the overall rostrocaudal extension of the ischemic CA1 infarct resolved to the best CA1 damage, and came to the conclusion that both volume estimation and scoring of overall neuropathology best reflected the ischemic damage.

Determination of VEGF Expression Using Western Blotting

Following transcardial perfusion with $250 \mathrm{ml}$ saline, the brains were isolated after decapitation under deep anesthesia and snapfrozen at $-80^{\circ} \mathrm{C}$ until homogenization in PBS ( $\mathrm{pH}$ 7.2) containing protease inhibitors (Complete, Mini; Roche, Penzberg, Germany). The tissue was disrupted using the Ultra-Turrax ${ }^{\circledR}$ T25 basic tissue homogenizer (Rose Scientific Ltd., Edmonton, Alta., Canada). The homogenates were pelleted by centrifugation at $13,000 \mathrm{~g}$ at $4^{\circ} \mathrm{C}$ for $20 \mathrm{~min}$, and the supernatants were removed for further analysis including total protein determination, using the Bradford protein assay kit (Thermo Scientific, Mass., USA), according to the manufacturer's instructions.

Homogenates $(30 \mu \mathrm{g}$ protein/lane) and the protein ladder (Pageruler; Fermentas, St. Leon-Rot, Germany) were loaded onto $12 \%$ Tris-glycine gels and transferred onto Hybond-P membranes (GE Healthcare, Little Chalfont, UK) using the mini-Protean electrophoresis system (Biorad, Hercules, Calif., USA). Following blocking (5\% skim milk powder; Sigma-Aldrich, St. Lou- is, Mo., USA), the membranes were incubated in primary antibody (mouse anti-rat VEGF antibody 1:100; Novus Biologicals, Littleton, Colo., USA) overnight at $4^{\circ} \mathrm{C}$, washed thoroughly and incubated with horseradish peroxidase-conjugated goat antimouse antibody (1:20,000; Jackson, Newmarket, UK) for $1 \mathrm{~h}$ followed by thorough washing. Chemiluminescence (Supersignal West Pico Chemiluminescent Substrate; Thermo Scientific, Rockford, Ill., USA) was detected on Hyperfilm ECL (GE Healthcare). The intensities of the bands on the films were measured using the software ImageJ (US National Institutes of Health, Bethesda, Md., USA). Ratios between VEGF and $a$-tubulin were calculated from these intensities, and the results are expressed relative to values from the control group. Western blotting was performed twice.

\section{Statistical Analysis}

Results are described as the mean $\pm \mathrm{SD}$, unless otherwise stated. Differences in physiological data were analyzed using Student's $t$ test. Correlation analyses between rectal and cranial window temperatures and the difference between rectal and cranial temperature and infarct size were performed using Spearman's rank correlation. Differences in infarct volumes between groups were analyzed using Student's $t$ test as saline and talipexole were alternately administered to the animals in all experimental groups. Changes in CA1 pyramidal cell damage were compared using the $\chi^{2}$ test. Differences in VEGF expression were analyzed using Student's t test. $p$ values $<0.05$ were considered significant.

Estimation of sample sizes in the MCAO model experiments was predicted from our previous results [13]. If the a (confidence level) and $\beta$ error levels (statistical power) were 5 and $50 \%$, respectively, groups required a sample size of 4 , and if $\alpha$ and $\beta$ were 5 and $20 \%$, respectively, groups required a sample size of 9 .

\section{Results}

\section{Preconditioning Experiments}

All animals subjected to 60 min MCAO and 2 days survival (fig. 1) had cortical infarcts in the left hemispheres which in the talipexole group measured 7.0 \pm 3.5 $\mathrm{mm}^{3}$ and in the saline group measured $26.8 \pm 9.3 \mathrm{~mm}^{3}$ (fig. 3). This difference between the infarct sizes in the two groups corresponded to a $74 \%$ reduction in infarct volume after regulated hypothermic preconditioning $(\mathrm{p}<$ 0.05 ). During the $20 \mathrm{~h}$ of infusion, the average body core temperature was $35.5 \pm 0.4^{\circ} \mathrm{C}$ in the talipexole group and $36.9 \pm 0.3^{\circ} \mathrm{C}$ in the saline group $(\mathrm{p}<0.05)$.

When global ischemia was induced 2 and 3 days after preconditioning (fig. 1), there was no statistical significance in the degree of hippocampal damage between the talipexole and the saline group (fig. 4). However, at 4 days after preconditioning, global ischemia induced significantly less damage to CA1 pyramidal cells $(\mathrm{p}<0.05)$ in those rats that received talipexole preconditioning (fig. 4). The difference in core body temperatures between tali- 


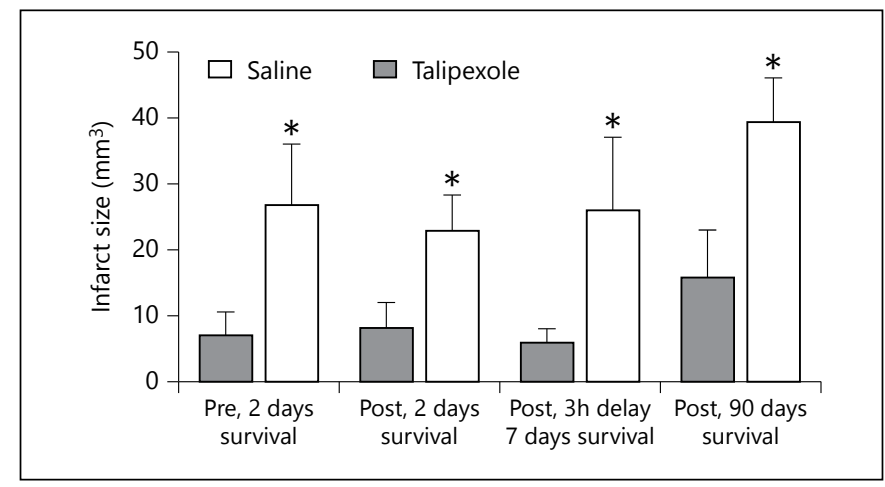

Fig. 3. Effect of treatment on infarct size following focal ischemia. Volumes of cortical infarctions following $60 \mathrm{~min}$ MCAO in various experimental groups, as indicated. Black bars represent the talipexole-induced hypothermic groups while white bars represent saline-treated normothermic rats. Details on groups and treatment are given in figures 1 and 2 . The mean \pm SD is shown for each experimental group. ${ }^{*} \mathrm{p}<0.05$, talipexole versus saline group. Pre $=$ Preconditioning; post $=$ postconditioning .

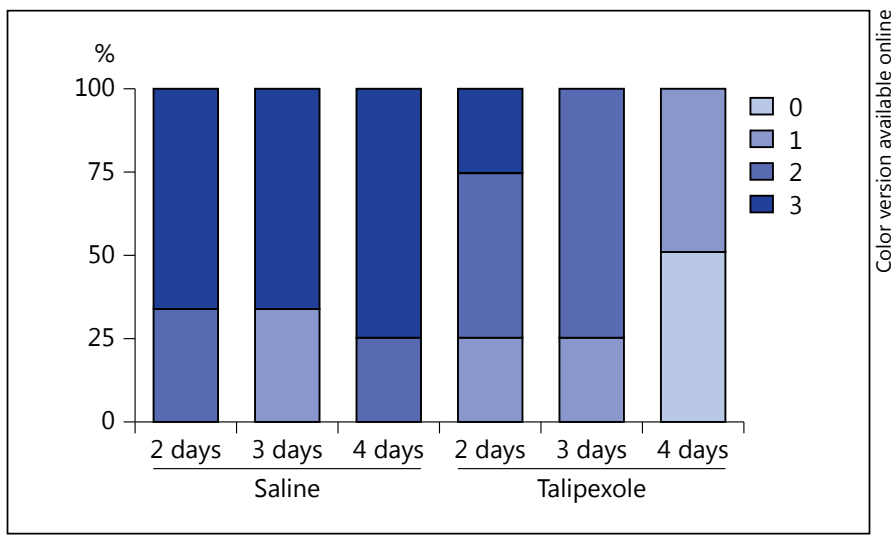

Fig. 4. Delayed effect of treatment on hippocampal CA1 damage following global ischemia. Animals had $20 \mathrm{~h}$ with talipexole-induced hypothermia or saline followed by 2 days ( $\mathrm{n}=4$ and 6 , respectively), 3 days ( $n=4$ and 3 ) or 4 days ( $n=4$ and 4 ) rest before they were subjected to $10 \mathrm{~min}$ of global ischemia and yet another 7 days of survival. The overall ischemic CA1 pyramidal cell damage was in agreement with previous verification [14] and scored as follows: $0=$ no ischemia, $1=$ mild ischemia, $2=$ moderate ischemia, and $3=$ severe ischemia. Four days after talipexole-induced hypothermic preconditioning, CA1 damage was significantly reduced compared to saline $(\mathrm{p}<0.05)$, as demonstrated by the brighter shades.

pexole and saline animals corresponded to a $1.2-1.3^{\circ} \mathrm{C}$ reduction during regulated hypothermic preconditioning (saline vs. talipexole; 2 days: $37.1 \pm 0.3^{\circ} \mathrm{C}$ vs. $35.9 \pm$ $0.6^{\circ} \mathrm{C} ; 3$ days: $37.2 \pm 0.3^{\circ} \mathrm{C}$ vs. $36.0 \pm 0.5^{\circ} \mathrm{C} ; 4$ days: $37.2 \pm$ $0.6^{\circ} \mathrm{C}$ vs. $35.9 \pm 0.4^{\circ} \mathrm{C}$; all $\left.\mathrm{p}<0.05\right)$.

Hypothermia in Experimental Stroke

\section{Postconditioning Experiments}

Infarct size in all animals subjected to $60 \mathrm{~min}$ MCAO measured $8.1 \pm 3.9 \mathrm{~mm}^{3}$ in the talipexole group and $22.9 \pm 5.4 \mathrm{~mm}^{3}$ in the saline group after 2 days survival (fig. 2, 3) and $15.8 \pm 7.2$ and $39.4 \pm 6.7 \mathrm{~mm}^{3}$ after 90 days survival (fig. 2, 3), corresponding to 65 and $60 \%$ reductions in infarct volumes comparing talipexole and saline groups, respectively $(\mathrm{p}<0.05)$. For animals with 2 days survival, during the $20 \mathrm{~h}$ of either talipexole postconditioning or saline infusion, the average core body temperatures were $35.1 \pm 1.1^{\circ} \mathrm{C}$ in the talipexole rats and $37.4 \pm 0.6^{\circ} \mathrm{C}$ in the saline rats $(\mathrm{p}<0.05$; fig. $5 \mathrm{a})$. For animals with 90 days survival, during the $20 \mathrm{~h}$ of infusion, the average core body temperature was $35.5 \pm$ $0.7^{\circ} \mathrm{C}$ in the talipexole rats and $36.9 \pm 0.5^{\circ} \mathrm{C}$ in the saline rats $(\mathrm{p}<0.05)$.

A therapeutic window of postconditioning with $3 \mathrm{~h}$ delay in drug infusion following reflow (fig. 2) showed a significant $78 \%$ decrease in infarct size $\left(5.9 \pm 2.1 \mathrm{~mm}^{3}\right.$ in the talipexole group vs. $26.1 \pm 11.0 \mathrm{~mm}^{3}$ in the saline group; $\mathrm{p}<0.05$, after 7 days survival; fig. 3 ).

\section{Proof of Principle of Experiment A: Clamping of Body Temperature}

During the $20 \mathrm{~h}$ of talipexole or saline administration together with temperature clamping (fig. 5b), average body core temperatures were not significantly different in the two groups $\left(37.0 \pm 0.5\right.$ vs. $37.1 \pm 0.3^{\circ} \mathrm{C}$ for the talipexole and saline groups, respectively). Keeping the animals normothermic resulted in infarct sizes that did not differ between the two groups $\left(42.8 \pm 12.2\right.$ vs. $43.1 \pm 7.8 \mathrm{~mm}^{3}$ for the talipexole and saline groups, respectively) after 7 days survival.

Proof of Principle of Experiment B: VEGF as a Marker for Conditioning

Since VEGF has been identified as one of the major beneficial players in conditioning $[16,17]$, we treated 4 rats with talipexole and 4 rats with saline followed by $24 \mathrm{~h}$ of survival. Without further treatment, brain homogenates were then investigated with Western blotting for the expression of VEGF (fig. 6). More than a doubling of VEGF expression levels was seen following talipexole administration compared to the saline group $(\mathrm{p}<0.05)$.

\section{Methodological Investigations of Experiment C: Blood Pressure}

Cumulated data ( $<24 \mathrm{~h}$ after surgery) from the mean arterial blood pressure after talipexole treatment in rats subjected to $60 \mathrm{~min} \mathrm{MCAO}$ was $133.4 \pm 15.0 \mathrm{~mm} \mathrm{Hg}$, and 


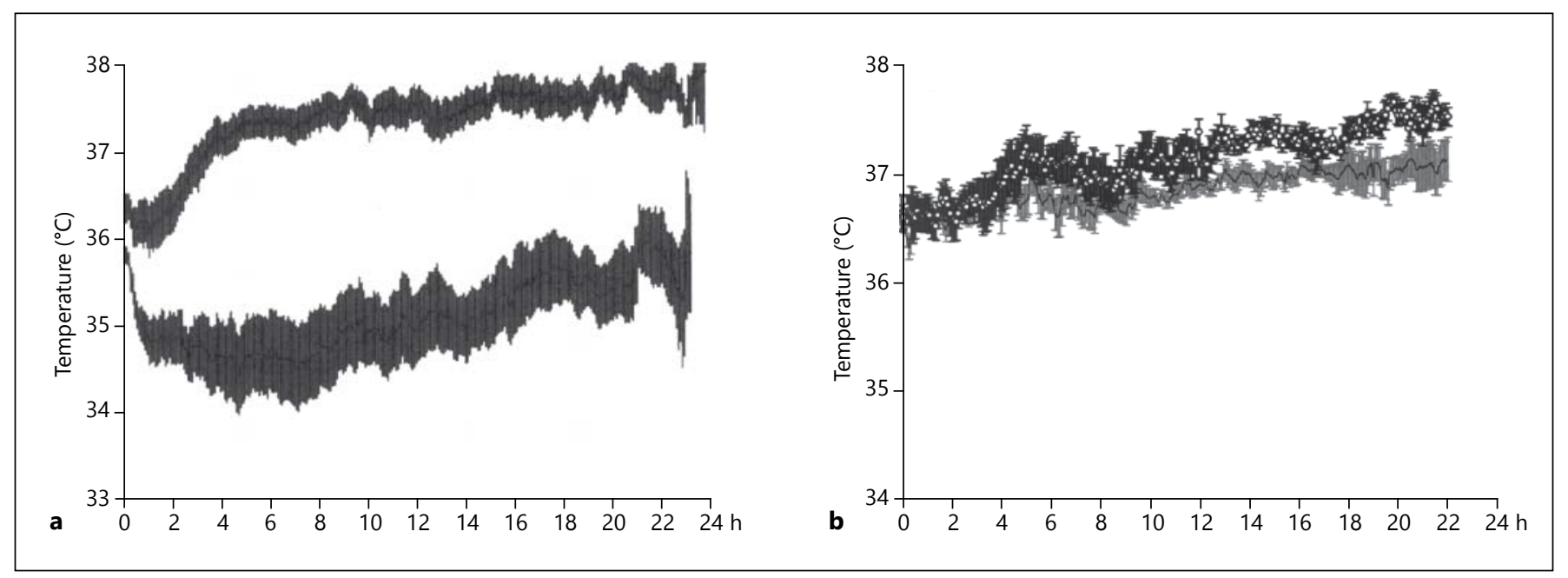

Fig. 5. Core body temperature during treatment. a Core body temperature as a function of time in saline (upper curve, $n=8$ ) and talipexole (lower curve, $\mathrm{n}=8$ ) treated rats recorded $30 \mathrm{~min}$ after the end of $60 \mathrm{~min}$ MCAO and during the next $22 \mathrm{~h}$. This is consistent with previously published work [13] and, as previously noted, the core body temperature returns to normal levels after drug withdrawal [13]. b Core body temperature as function of time in saline (upper

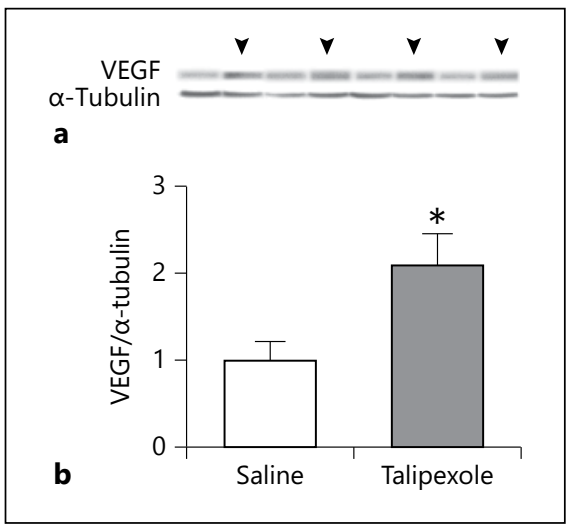

Fig. 6. Semiquantitative determination of VEGF expression. a VEGF expression in brain homogenates from rats without ischemia subjected to talipexole-induced hypothermia ( $\mathrm{n}=4$, arrows) or saline infusion $(n=4)$. b VEGF expression (approximately 25 $\mathrm{kDa}$ ) relative to loading control ( $\alpha$-tubulin, approximately $50 \mathrm{kDa}$ ) is quantified. Data are given as the mean \pm SEM from two separate Western blot experiments. ${ }^{*} \mathrm{p}<0.05$, talipexole versus saline group.

in the sham-operated group, it was $123.2 \pm 13.0 \mathrm{~mm} \mathrm{Hg}$; these figures were not statistically different $(\mathrm{p}>0.05)$. Measurements were performed in freely moving rats, and figures are not different from measurements in rats subjected to moderate stress reported by others [18]. curve, $\mathrm{n}=5$ ) and talipexole (lower curve, $\mathrm{n}=7$ ) treated rats recorded $30 \mathrm{~min}$ after the end of $60 \mathrm{~min} \mathrm{MCAO}$ and during the next $22 \mathrm{~h}$ when animals are kept normothermic by maintaining the temperature between 37.0 and $38.0^{\circ} \mathrm{C}$ with a thermoregulated heating lamp and fan. Note that the initial drop in temperature seen in rats without temperature regulation (a, upper curve) after MCAO is abolished in $\mathbf{b}$ (upper curve). The mean \pm SD is shown for each experimental group.

Methodological Investigations of Experiment D: Rectal and Cranial Window Temperatures

Rectal and cranial window temperatures were simultaneously registered during the $60 \mathrm{~min} \mathrm{MCAO}$, with average temperatures as shown in figure 7a. Results showed that both temperature curves followed the same pattern. Figure $7 \mathrm{~b}$ depicts the average cranial window temperature versus the infarct size in each animal. There was no statistically significant correlation between cranial window temperature and infarct size. Finally, figure $7 \mathrm{c} \mathrm{dem}$ onstrates the difference between the average rectal and cranial window temperatures versus the infarct size in each animal; results showed that there was no statistically significant correlation between temperature differences and infarct size.

\section{Animal Exclusions and Mortality}

In the preconditioning studies, 1 saline rat died during surgery, and 1 saline and 2 talipexole rats were excluded because of subcortical infarcts. In the postconditioning studies, 4 saline and 2 talipexole rats died during surgery, and 3 talipexole rats were excluded because of subcortical infarcts. In additional experiment A, 2 saline rats died during surgery, and in experiment $C, 1$ saline rat died during surgery.
48
Johansen et al. 
Fig. 7. Influence of the open cranial window on brain temperature and infarct size. a Rectal and cranial window temperatures (Tcw) were simultaneously registered during 60 min MCAO $(n=9$, mean temperatures). The two temperature curves nicely reflect one another. b Cranial window temperature versus infarct size in each animal is plotted. No statistically significant correlation $(\mathrm{p}>0.05)$ between cranial window temperature and infarct size was found. c The difference between the rectal and cranial window temperatures versus the infarct size in each animal is plotted. There was no statistically significant correlation between temperature differences and infarct size.

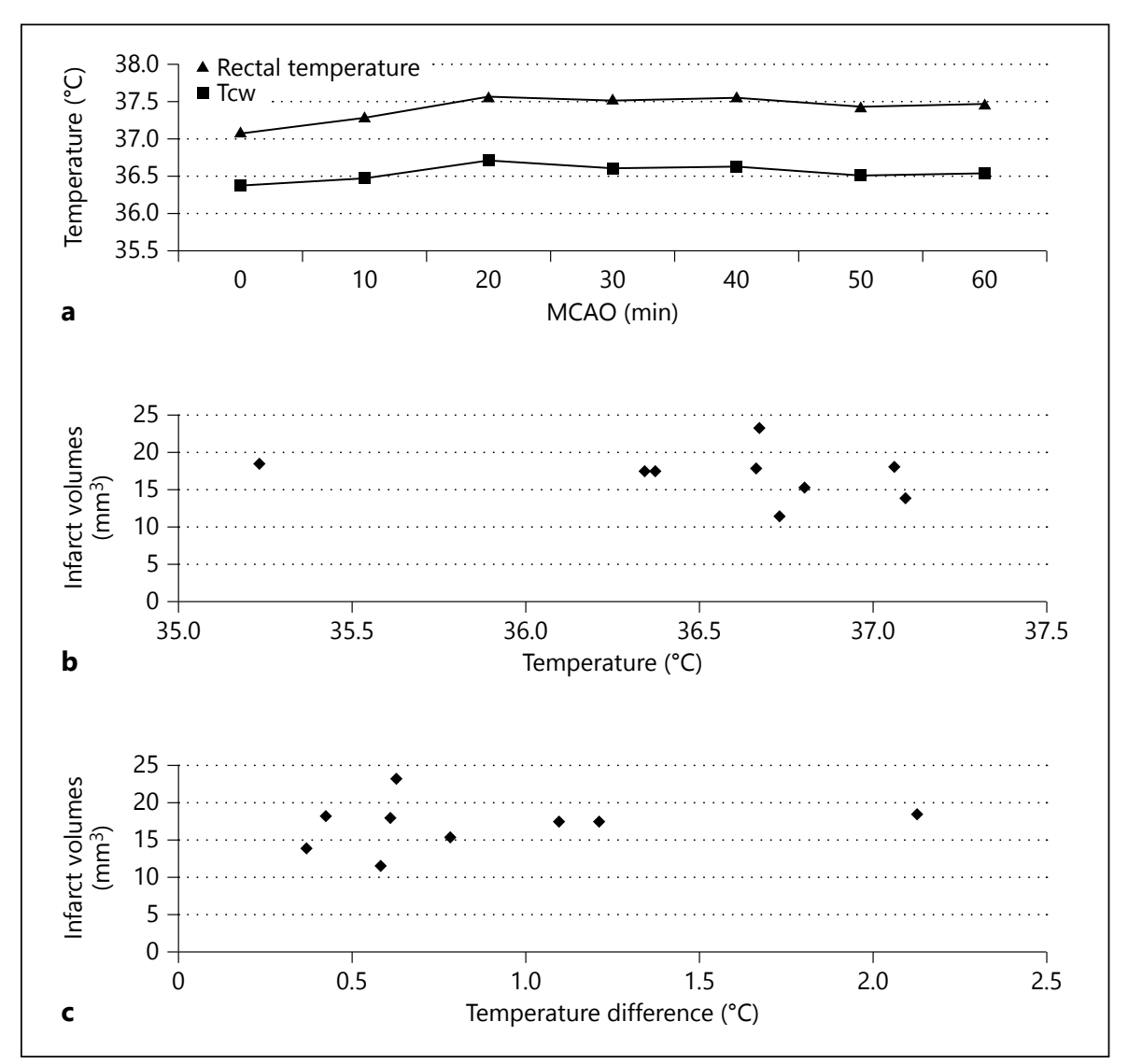

\section{Physiological Data}

Physiological data from arterial blood was collected just before, during and immediately after global and focal cerebral ischemia. Physiological data from both the global [14] and the focal ischemia model $[13,14]$ have been reported and discussed in detail previously, and results in this study are not different from these reports. Within each experimental group, data from talipexole- and saline-treated groups were compared: variations between these data corresponding to $\mathrm{pCO}_{2}, \mathrm{pO}_{2}$, sodium, potassium, $\mathrm{pH}$, and glucose as well as interischemic body temperature and mean arterial blood pressure during the operation were not statistically significant $(\mathrm{p}<0.05)$.

\section{Discussion}

\section{Therapeutic Drug-Induced Hypothermia Applied}

before and after Cerebral Ischemia

Our major finding was a long-term infarct reduction following talipexole-induced hypothermia, both when mild hypothermia was initiated before and up to $3 \mathrm{~h}$ after reperfusion in rodent models of focal and global ischemia. Hypothermia has been shown to mediate crosstolerance towards ischemia when used as a preconditioning stimulus [4]. In our model of talipexole-induced hypothermia, we also demonstrated neuroprotection when talipexole-induced hypothermia was completed hours before focal as well as global ischemia. Conditioning was further supported in our study by the finding of VEGF induction in the brain after talipexole-induced hypothermia $[16,17]$. In line with showing (pre)conditioning effects of talipexole-induced hypothermia, the more broad-term postconditioning [19] can be used for poststroke talipexole-induced hypothermia. We anticipate an effect from the hypothermia stretching beyond the time of treatment, which is supported by the fact that postischemic hypothermia has been shown to alter gene expressions [20,21]. Again, when talipexole was administered after reperfusion, results showed a $65-60 \%$ reduction in infarct size after 2 and 90 days survival, respectively.

As anticipated, we observed a slight progression in infarct size up to 90 days after the insult, but still, the infarct 
reduction was significant and substantial. Pioneer studies showed that physiologically forced cooling after ischemia only reduced infarct size temporarily for the first 7 days but not after 60 days survival. However, when interischemic hypothermia was applied, the neuroprotection remained 60 days after the insult [22]. Thus, long-term survival studies must ensure that significant pathological mechanisms are irreversibly terminated and not just delayed, a test that our study passed, possibly because of both a prolonged period of $20 \mathrm{~h}$ of hypothermia and a less stressful regulated hypothermia without counter-regulation.

Investigating the therapeutic window, a 3-hour delay in treatment after stroke also significantly reduced infarct size. However, when temperature reduction was eliminated during talipexole treatment by keeping the rats normothermic with a heating lamp, the reduction in infarct size did not materialize. It is therefore most likely the hypothermia in itself and not other effects from the talipexole that are primarily responsible for the reduced brain damage. This is further strengthened by our measures of an unchanged blood pressure in talipexole-treated rats as compared to controls.

\section{Experimental Models for Studying Regulated}

Hypothermia in Cerebral Ischemia

In experimental stroke, one can question the relevance of the model. We have previously and now chosen a reversible focal stroke model that reproducibly results in cortical infarcts of small to medium size $\left(<45 \mathrm{~mm}^{3}\right)$ leaving the thermoregulatory hypothalamic preoptic nucleus undamaged [23]. In figures, 83 rats entered our $60-\mathrm{min}$ MCAO model out of which 8 died during surgery and 6 were discarded because in addition to cortical infarcts, they had subcortical infarcts. Therefore, we find our model suited for studies of regulated drug-induced hypothermia. In contrast, models of permanent MCAO and intraluminal filament MCAO also damage subcortical thermoregulatory structures $[24,25]$ with induction of hyperthermia [26] as an inappropriate result. When we performed coordinated measurements of both rectal and cranial window temperature during surgery in relation to infarct development in our model, it clearly showed that variations in cranial window temperature had no influence on the infarct size.

Nishio et al. $[4,27]$ demonstrated a significant reduction in infarct size by forced hypothermic preconditioning initiated $24 \mathrm{~h}$ before MCAO. Therefore, we also started induction of regulated hypothermic preconditioning at $26 \mathrm{~h}$ before MCAO and we obtained similar results. In our global ischemia model, a typical late-phase neuroprotection [3] was seen on day 4 after hypothermic preconditioning. This time frame is in agreement with the original reports by Kato et al. [28], Kirino et al. [29] and Kitagawa et al. [30]. Interestingly, it has been shown that infarct protection afforded by postconditioning is as effective as that afforded by preconditioning [31]. This was confirmed by our results when comparing for example pre- and postconditioning in MCAO with 2 days survival.

\section{Dopamine-Induced Hypothermia in Stroke}

Hypothermia is a common side effect of numerous drugs [32]. Dopamine plays a key role in temperature regulation in the preoptic medial hypothalamic nucleus [23, 33 , and dopamine is in general either directly or indirectly involved when drug-induced hypothermia occurs [33]. As an example, we have previously demonstrated neuroprotection following cannabinoid-induced hypothermia [14] which is related to endogenously released dopamine [34]. In fact, core temperature measurement in rats, reflecting intrinsic efficacy at dopamine receptors $[35,36]$, is used for drug screening in the industry. Various dosages were initially tested to find a treatment that in our model induced $1.2-2.3^{\circ} \mathrm{C}$ temperature reduction during the first $20 \mathrm{~h}$ of administration. Remarkably, continuation of talipexole administration beyond $20 \mathrm{~h}$ could not prevent the core body temperature from returning to normothermia [13]. The very same was seen after continuous slow cannabinoid injection [14] pointing towards a common dopaminergic thermoregulation as mentioned [34]. The dopaminergic $\mathrm{D}_{2}-\mathrm{D}_{3}$ agonist talipexole may also in part gain its hypothermic effect from additional 2 -adrenoreceptor agonist effects $[37,38]$.

Indeed, translating the dose from experimental rat studies directly to humans simply based on body weight revealed that prolonged hypothermia in patients would require doses more than a hundredfold of current recommendations (maximum $3.5 \mathrm{mg} /$ day). The only observation on hypothermia in humans following talipexole treatment was reversible hypothermia of $35.4{ }^{\circ} \mathrm{C}$ in a 55-year-old male with Parkinson's disease who took a daily dose of $2 \mathrm{mg}$ talipexole [39]. This may indicate that sufficient mild temperature reductions occur in humans using much lower talipexole doses than in rats $[40,41]$. Dopamine receptor agonists for Parkinson's disease frequently (approximately 30\%) cause nausea and vomiting triggered by dopamine receptors [42]. More serious adverse events are the risk of causing psychosis [43-45]. In that context, the use of dopamine agonists in rats may result in stereotypic behaviors $[46,47]$, but we did not
Johansen et al. 
observe behavioral stereotypes in the talipexole-treated rats.

Finally, it remains possible that talipexole additionally conveys a neuroprotective effect independent of hypothermia [48]: attenuation of glutamate neurotoxicity [49], inhibition of apoptosis [50] and increased superoxide dismutase antioxidant activity [51] are among the mechanisms suggested.

\section{Implications of Drug-Induced Hypothermia in Stroke}

The overall purpose of our studies was to investigate in animal models if mild drug-induced hypothermia in a clinical setting might be useful before neuro- and cardiac surgical procedures and, after stroke, to ameliorate ischemic brain damage. We exemplified this perspective by choosing the clinically approved drug talipexole and speculate that drug-induced regulated mild hypothermia may cause less severe, and easier-to-treat, adverse events than forced mechanical cooling. Furthermore, drug-induced cooling can be initiated instantly and anywhere also outside of hospitals. Since hypothermia is a common side effect to many registered drugs, we suggest that more attention is directed towards this perspective. Briefly, these drugs are serotonergic $5 \mathrm{HT}_{1 \mathrm{~A}}$ agonists, dopaminergic $\mathrm{D}_{2}$ agonists and possibly also $\alpha_{2}$-receptor agonists with hypothermic regulatory actions in the brain, as well as drugs like 2-deoxy-glucose and iodine solution with direct and indirect effects on metabolic heat production, and finally, maybe also $\alpha_{1}$-receptor antagonists with selective peripheral vasodilator effects increasing heat loss.

\section{Acknowledgements}

This work was kindly supported by the following foundations: Mindefonden for Alice Brenaa, Civilingeniør Frode Nygaard and Hustrus Fond, Direktør Emil C. Hertz and Hustru Inger Hertz's Fond, Kong Christian den Xs Fond, Aase and Ejnar Danielsens Fond, Arvid Nilssons Fond, Fru Asta Bildings Mindelegat, Lykfeldts Legat, Ivan Nielsens Fond, Forskningsrådet for Sundhed og Sygdom (No. 271-05-0327), Lundbeckfonden (No. 236/05). The technical assistance of Lisbeth Thatt, Natasha Fauerby, Heidi Maria Paulsen, and Lise Schorling Strange is greatly acknowledged.

\section{Disclosure Statement}

The authors have no conflict of interest.

\section{References}

1 Hacke W, Kaste M, Bluhmki E, Brozman M, Dávalos A, Guidetti D, Larrue V, Lees KR, Medeghri Z, Machnig T, Schneider D, von Kummer R, Wahlgren N, Toni D, ECASS Investigators: Thrombolysis with alteplase 3 to $4.5 \mathrm{~h}$ after acute ischemic stroke. $\mathrm{N}$ Engl J Med 2008;359:1317-1329.

-2 Newman MF, Kirchner JL, Phillips-Bute B, Gaver V, Grocott H, Jones RH, Mark DB, Reves JG, Blumenthal JA, Neurological Outcome Research Group and the Cardiothoracic Anesthesiology Research Endeavors Investigators: Longitudinal assessment of neurocognitive function after coronary-artery bypass surgery. N Engl J Med 2001;344:395-403.

- 3 Kirino T: Ischemic tolerance. J Stroke Cerebrovasc Dis 2002;22:1283-1296.

-4 Nishio S, Masatoshi Y, Zong-Fu C, Anzivino MJ, Lee KS: Ischemic tolerance in the rat neocortex following hypothermic preconditioning. J Neurosurg 2003;93:845-851.

5 O'Collins VE, Macleod MR, Donnan GA, Horky LL, van der Worp BH, Howells DW: 1,026 experimental treatments in acute stroke. Ann Neurol 2006;59:467-477.

6 Liu L, Yenari MA: Therapeutic hypothermia: neuroprotective mechanisms. Front Biosci 2007;12:816-825.

7 Yunoki M, Nishio S, Ukita N, Anzivino MJ, Lee KS: Characteristics of hypothermic preconditioning influencing the induction of de- layed ischemic tolerance. J Neurosurg 2002; 15 Swanson RA, Morton MT, Tsao-Wu G, 97:650-657.

8 Yunoki M, Nishio S, Ukita N, Anzivino MJ, Lee KS: Hypothermic preconditioning induces rapid tolerance to focal ischemic injury in the rat. Exp Neurol 2003;181:291-300.

-9 Kammersgaard LP, Jørgensen HS, Rungby JA, Reith J, Nakayama H, Weber UJ, Houth J, Olsen TS: Admission body temperature predicts long-term mortality after acute stroke: the Copenhagen Stroke Study. Stroke 2002; 33:1759-1762.

10 Wang Y, Lim LL, Levi C, Heller RF, Fisher J: Influence of admission body temperature on stroke mortality. Stroke 2000;31:404-409.

11 Hemmen TM, Lyden PD: Induced hypothermia for acute stroke. Stroke 2007;38:794-799.

12 van der Worp HB, Sena ES, Donnan GA, Howells DW, Macleod MR: Hypothermia in animal models of acute ischaemic stroke: a systematic review and meta-analysis. Brain 2007;130:3063-3074.

13 Johansen FF, Jørgensen HS, Reith J: Prolonged drug-induced hypothermia in experimental stroke. J Stroke Cerebrovasc Dis 2003; 12:97-102.

14 Bonfils PK, Reith J, Hasseldam H, Johansen FF: Estimation of the hypothermic component in neuroprotection provided by cannabinoids following cerebral ischemia. Neurochem Int 2006;49:508-518. Savalos RA, Davidson C, Sharp FR: A semiautomated method for measuring brain infarct volume. J Cereb Blood Flow Metab 1990;10: 290-293.

16 Nijsen MJ, Ongenae NG, Coulie B, Meulemans AL: Telemetric animal model to evaluate visceral pain in the freely moving rat. Pain 2003; 105:115-123.

17 Wick A, Wick W, Waltenberger J, Weller M, Dichgans J, Schulz JB: Neuroprotection by hypoxic preconditioning requires sequential activation of vascular endothelial growth factor receptor and Akt. J Neurosci 2002;22: 6401-6407.

18 Fang J, Chen L, Fan L, Wu L, Chen X, Li W, Lin Y, Wang W: Enhanced therapeutic effects of mesenchymal stem cells on myocardial infarction by ischemic postconditioning through paracrine mechanisms in rats. J Mol Cell Cardiol 2011;51:839-847.

19 Zhao H: The protective effects of ischemic postconditioning against stroke: from rapid to delayed and remote postconditioning. Open Drug Discov J 2011;5:138-147.

20 Pabello NG, Tracy SJ, Snyder-Keller A, Keller RW Jr: Regional expression of constitutive and inducible transcription factors following transient focal ischemia in the neonatal rat: influence of hypothermia. Brain Res 2005; 1038:11-21. 
21 Ohta H, Terao Y, Shintani Y, Kiyota Y: Therapeutic time window of post-ischemic mild hypothermia and the gene expression associated with the neuroprotection in rat focal cerebral ischemia. Neurosci Res 2007;57:424-433.

-22 Dietrich WD, Busto R, Alonso O, Globus MY-T, Ginsberg MD: Intra-ischemic but not postischemic brain hypothermia protects chronically following global forebrain ischemia in rats. J Cereb Blood Flow Metab 1993;13:541-549.

23 Durukan A, Tatlisumak T: Acute ischemic stroke: overview of major experimental rodent models, pathophysiology, and therapy of focal cerebral ischemia. Pharmacol Biochem Behav 2007;87:179-197.

- 24 Gerriets T, Stolz E, Walberer M, Kaps M, Bachmann G, Fisher M: Neuroprotective effects of MK-801 in different rat stroke models for permanent middle cerebral artery occlusion: adverse effects of hypothalamic damage and strategies for its avoidance. Stroke 2003; 34:2234-2239.

25 Li F, Omae T, Fisher M: Spontaneous hyperthermia and its mechanism in the intraluminal suture middle cerebral artery occlusion model of rats. Stroke 1999;30:2464-2470.

26 Popp A, Jaenisch N, Witte OW, Frahm C: Identification of ischemic regions in a rat model of stroke. PLoS ONE 2009;4:e4764.

27 Nishio S, Chen ZF, Yunoki M, Toyoda T, Anzivino M, Lee KS: Hypothermia-induced ischemic tolerance. Ann NY Acad Sci 1999; 890:26-41.

28 Kato H, Liu Y, Araki T, Kogure K: Temporal profile of the effects of pretreatment with brief cerebral ischemia on the neuronal damage following secondary ischemic insult in the gerbil: cumulative damage and protective effects. Brain Res 1991;553:238-242.

29 Kirino T, Tsujita Y, Tamura A: Induced tolerance to ischemia in gerbil hippocampal neurons. J Cereb Blood Flow Metab 1991;11:299307.

30 Kitagawa K, Matsumoto M, Kuwabara K, Tagaya M, Ohtsuki T, Hata R, Ueda H, Handa N, Kimura K, Kamada T: 'Ischemic tolerance' phenomenon detected in various brain regions. Brain Res 1991;561:203-211.
31 Zhao ZQ, Corvera JS, Halkos ME, Kerendi F, Wang NP, Guyton RA, Vinten-Johansen J: Inhibition of myocardial injury by ischemic postconditioning during reperfusion: comparison with ischemic preconditioning. Am J Physiol Heart Circ Physiol 2003;285:579-588.

32 Clark WG, Clark YL: Changes in body temperature after administration of antipyretics, LSD, Ag-TCH, CNS depressants and stimulants, hormones, inorganic ions, gases, 2,4DNP and miscellaneous agents. Neurosci Biobehav Res 1981;5:1-136.

33 Cox B, Lee TF: Evidence for an endogenous dopamine-mediated hypothermia in the rat. Br J Pharmacol 1979;67:605-610.

4 Nava F, Carta G, Gessa GL: Permissive role of dopamine $\mathrm{D}(2)$ receptors in the hypothermia induced by delta(9)-tetrahydrocannabinol in rats. Pharmacol Biochem Behav 2000;66:183187.

35 Salmi P, Jimenez P, Ahlenius S: Evidence for specific involvement of dopamine $D_{1}$ and $D_{2}$ receptors in the regulation of body temperature in the rat. Eur J Pharmacol 1993;236: 395-400.

-36 Salmi P: Independent roles of dopamine $\mathrm{D}_{1}$ and $\mathrm{D}_{2 / 3}$ receptors in rat thermoregulation. Brain Res 1998;781:188-193.

37 Sanchez C, Amt J: Effects on body temperature in mice differentiate between dopamine $\mathrm{D}_{2}$ receptor agonists with high and low efficacies. Eur J Pharmacol 1992;211:9-14.

-38 Anden NE, Golembiowska-Nikiten K, Thomström U: Selective stimulation of dopamine and noradrenaline autoreceptors by B-HT 920 and B-HT 933, respectively. Naunun Schmiedebergs Arch Pharmacol 1982;32: 100-104.

39 Nobuyoshi Kodani, Boehringer Ingelheim, personal communication, 2000

40 Knoll T, Wimmer ML, Gumpinger F, Haberl RL: The low normothermia concept - maintaining a core body temperature between 36 and 37 degrees $C$ in acute stroke unit patients. J Neurosurg Anesthesiol 2002;14:304-308.

41 The Hypothermia after Cardiac Arrest Study Group: Mild therapeutic hypothermia to improve the neurological outcome after cardiac arrest. N Engl J Med 2002;346:549-556.

$\checkmark 42$ Hsu WH, Schaffer DD, Dyer DC: The emetic effect of B-HT 920 and apomorphine in the dog: antagonism by haloperidol. Life Sci 1986; 39:1021-1026.
43 Cummings JL: Neuropsychiatric complications of drug treatment in Parkinson's disease; in Huber S, Cummings JL (eds): Parkinson's Disease: Neurobehavioral Aspects. New York, Oxford University Press, 1992, pp 313327.

44 Giladi N, Treves TA, Paleacu D, Shabtai H, Orlov Y, Kandinov B, Simon ES, Korczyn AD: Risk factors for dementia, depression, and psychosis in long-standing Parkinson's disease. J Neural Transm 2000;10:759-771.

45 Aarsland D, Larsen JP, Cummings JL, Laake $\mathrm{K}$ : Prevalence and clinical correlates of psychotic symptoms in Parkinson disease: a community-based study. Arch Neurol 1999;56: 595-601.

46 Wallace TL, Gudelsky GA, Vorhees CV: Methamphetamine-induced neurotoxicity alters locomotor activity, stereotypic behavior, and stimulated dopamine release in the rat. J Neurosci 1999;19:9141-9148.

47 Rasmussen RS, Overgaard K, HildebrandtEriksen ES, Boysen G: D-amphetamine improves cognitive deficits and physical therapy promotes fine motor rehabilitation in a rat embolic stroke model. Acta Neurol Scand 2006;113:189-198.

48 Bozzi Y, Borrelli E: Dopamine in neurotoxicity and neuroprotection: what do $\mathrm{D}_{2}$ receptors have to do with it? Trends Neurosci 2006;29: 167-174.

49 Sawada H, Ibi M, Kihara T, Urushitani M, Akaike A, Kimura J, Shimohama S: Dopamine $\mathrm{D}_{2}$-type agonists protect mesencephalic neurons from glutamate neurotoxicity: mechanisms of neuroprotective treatment against oxidative stress. Ann Neurol 1998;44: 110-119.

50 Ukai W, Ozawa H, Tateno M, Hashimoto E, Saito T: Neurotoxic potential of haloperidol in comparison with risperidone: implication of Akt-mediated signal changes by haloperidol. J Neural Transm 2004;111:667-681.

51 Iida M, Miyazaki I, Tanaka K, Kabuto H, Iwata-Ichikawa E, Ogawa N: Dopamine $\mathrm{D}_{2}$ receptor-mediated antioxidant and neuroprotective effects of ropinirole, a dopamine agonist. Brain Res 1999;838:51-59. 